\title{
Mantra Yoga: An Overview
}

\author{
Ajay Bhardwaj* \\ Department of Communication, India
}

Submission: August 19, 2019; Published: November 19, 2019

*Corresponding author: Ajay Bhardwaj, Department of Communication, DSVV, Haridwar, India

Abstract

A Mantra is divinity encased within a sound-structure. It is divine power manifesting in a sound-body. The Mantra is itself Devta(deity). The sacred Mantra or the Divine Name is a vital symbol of the Supreme Divinity directly revealed to the seers in the state of deep meditation and trace. These symbols are in the nature of unfailing keys to gain access into the transcendental realms of absolute experience. By the practice of mantra japa, the aspirant's conscious will is awakened and through the willpower everything is accomplished. Different mantras have different benefits. All those who practice japa of Gayatri mantra will find it very beneficial for the health and intellect. For skin diseases or iron deficiency, anushthana of the Surya or Sun mantras is beneficial if practiced properly.

Keywords: Mantra; Sound structure; Sacred; Divine name; Japa; Absolute

\section{Introduction}

Mantra occupies a prominent place in Vedic religion and Indian Culture. Since time immemorial saints, seers, sages and Yogis have been practicing Mantra Yoga for spiritual enlightenment. Vedas, the core of Indian culture consist of various mantras for the accomplishment of various purposes. Mantras are used as sacred sounds or utterances. Since they are taken from the sacred texts, they are considered auspicious and God in word form. They are used in ritual and spiritual practices and various sacrificial ceremonies. We have the description of 16 types of sanskars or ceremonies in Vedic scriptures. Each ceremony is performed with a different mantra. Our every festival is celebrated by chanting different mantras. We can't imagine of the celebration of any festivals and ceremonies without the chanting of mantras in Vedic religion.

Mantras are used both for the attainment of physical, material and spiritual goals and purposes. There are various types of mantras like Om Namo Bhagavate Vasudevaya, Om Namah Shivaya, the Mahamrityunjaya mantra, the Gayatri mantra etc. These are common mantras or universal mantras, which anybody can use for a specific purpose [1,2]. The Maha Mrityunjaya Mantra (for increasing health of body and mind) and the Gayatri Mantra (for increasing creative energy and pranic energy) are examples of this. Anyone may choose to adopt and chant these mantras.

$\mathrm{OM}$ is considered the source (basis) of all the mantras. It is the highest and the purest and Brahman himself in word form (Sabda Brahma). It is also known as mantra Purusha (God as mantra). It has the potency to divinize and purify all other verbal expressions and word forms. Hence, it is often used as a prefix to all other mantras to infuse them divine power and purity. Therefore, Mantras constitute the core of Vedic religion and the divine culture of India.

\section{Meaning, Concept and Importance}

A mantra is a revealed word, a divine sound that has been received or experienced by Vedic seers in the state of deep meditation and trance. It is a condensed form of spiritual divine energy. Mantra is a sacred formula, it is a subtle form of a deity, sound/vibration. Mantra refers to a "mystical formula" regarding some deity.'Mananat-trayate iti Mantrah'-By the Manana (constant thinking or recollection) of which one is protected or is released from the round of births and deaths, is Mantra. That is called Mantra by the meditation (Manana) on which the Jiva or the individual soul attains freedom from sin, enjoyment in heaven and final liberation, and by the aid of which it attains in full the fourfold fruit (Purushartha chatustya), i.e., Dharma, Artha, Kama and Moksha. A Mantra is so called because it is achieved by the mental process. The root 'Man' in the word Mantra comes from the first syllable of that word, meaning 'to think', and 'Tra' from 'Trai' meaning 'to protect' or 'free' from the bondage of Samsara or the phenomenal world. By the combination of 'Man' and 'Tra' comes Mantra.

a) Lord krishna says: Among words I am the sacred syllable OM. Among offerings, I am the offering of Japa (chanting of mantra or sacred formulas [3]. 
b) Maharshi patanjali says: OM is the word denoting God. Pranav (OM) is the crown of all mantras. We should contemplate it again and again as it is a great power [4].

c) Swami Vivekananda very brilliantly argues: What are Mantras? The whole of this universe has, according to Indian philosophy, both name and form (Nâma-Rupa) as its conditions of manifestation. In the human microcosm, there cannot be a single wave in the mind-stuff (Chittavritti) unconditioned by name and form. If it be true that nature is built throughout on the same plan, this kind of conditioning by name and form must also be the plan of the building of the whole of the cosmos. «As one lump of clay being known, all things of clay are known», so the knowledge of the microcosm must lead to the knowledge of the macrocosm $[5,6]$.

Now form is the outer crust, of which the name or the idea is the inner essence or kernel. The body is the form, and the mind or the Antahkarana is the name, and sound-symbols are universally associated with Nâma (name) in all beings having the power of speech. In the individual man the thought-waves rising in the limited Mahat or Chitta (mind-stuff), must manifest themselves, first as words, and then as the more concrete forms. In the universe, Brahmâ or Hiranyagarbha or the cosmic Mahat first manifested himself as name, and then as form, i.e. as this universe. All this expressed he form, behind which stands the eternal inexpressible Sphota, the manifester as Logos or Word. This eternal Sphota, the essential eternal material of all ideas or names is the power through which the Lord creates the universe, nay, the Lord first becomes conditioned as the Sphota, and then evolves Himself out as the yet more concrete sensible universe. This Sphota has one word as its only possible symbol, and this is the ? $(\mathrm{Om})$., it is out of this holiest of all holy words, the mother of all names and forms, the eternal $\mathrm{Om}$, that the whole universe may be supposed to have been created.

a) Sri raman maharshi observes: Mantras (repeating sacred syllables) or formula as a means to realize the Self. The mind is a channel, a swift current of thoughts. A mantra is a bund or dam put up in the way of this current to divert the water where it is needed.

b) Sri aurobindo remarks: The theory of the Mantra is that it is a word of power born out of the secret depths of our being where it has been brooded upon by a deeper consciousness than the mental, framed in the heart and not constructed by the intellect, held in the mind, again concentrated on by the waking mental consciousness and then thrown out silently or vocally - the silent word is perhaps held to be more potent than the spoken - precisely for the work of creation.

c) The Mantra can not only create new subjective states in ourselves, alter our psychical being, reveal knowledge and faculties we did not before possess, can not only produce similar results in other minds than that of the user, but can produce vibrations in the mental and vital atmosphere which result in effects, in actions and even in the production of material forms on the physical plane. Mantra is creation by Word. The word is a sound expressive of the idea. In the supra-physical plane when an idea has to be realized, one can by repeating the word-expression of it, produce vibrations which prepare the mind for the realization of the idea. That is the principle of the Mantra and of japa. One repeats the name of the Divine and the vibrations created in the consciousness prepare the realization of the Divine. It is the same idea that is expressed in the Bible, "God said, let there be Light, and there was Light." It is creation by the Word.

d) Swami Vishnu-devananda says: "A mantra is a mystical energy encased in a sound structure ... It steadies the mind and leads to the stillness of meditation.' (Meditation and Mantra).

e) As stated by swami satyananda saraswati: Mantras are "purpose-specific", that is, each mantra, whether Bija or a more elaborate construction of separate mantra, is used to realize specific results. Health, prosperity, spiritual realization and social stability are examples of such objectives. As a result, individuals choose to recite or chant different mantras according to their needs. It is important to note however, that one must never alter the mantra. If done, it is no longer a mantra and its power is lost. It becomes just sounds. Also, Mantra Japs must be done mindfully and with respect. The practice should be regular and exist for the practitioner with the same observances as is given to other daily practices. For example, we typically follow a specific schedule concerning our diet [7-14]. This is done to ensure proper and constant nutrition to our bodies. We should treat mantras the same way. It should be done regularly at prescribed times and for a specific length of time. In this way, we can expect to gain realization through the mantras transformative inner power. As the rishis sat in meditation and reached higher levels, they received the sounds known as mantra. Mantras, therefore, are not a creation of the human mind. They were perceived from higher sources. In Islam it is said that the Koran was revealed by God, which means that whoever received the Koran had attained a very high yogic state. In the same way, Christians speak of the Bible as a revealed scripture. Sanatana dharma, the eternal vedic religion, too is understood as having been revealed. The Vedas were not written by man. This, however, does not mean that the pen that wrote them was held in God's hand; it only means that they were revealed to rishis in the transcendental state. The same is said about the Ramacharitamanas. (Saraswati,Swami Satyananda,2007) [15].

\section{Elements of Mantra}

There are five elements of a Mantra. They are: Rishi (Seer), Chhanda (meter), Devta (deity), Bija (seed), and Tattva (element).

a. Rishi (Seer): There were ancient seers and sages, who had the actual realization of mantra. In meditation, when the rishis were able to transcend the material consciousness, rising 
to a very high level, those sounds heard by them in that highest state were called mantra. Every Mantra has a Rishi. Rishi means the seer who got that mantra through divine vision (darshana) for the first time and got sidhi or perfection in that mantra. Some rishis also discover mantras, and then they become the rishi of that mantra. The seer is a spiritual scientist who firstly makes experiments with mantra in the laboratory of his own body, mind and spirit and there after he helps others in making such experiments. (SRSAV-14, P.3.22).

b. Chanda: Meter, which is technically very specific for each mantra. It is actual pronunciation of that mantra and its meter or the science behind the meter. That is "how" the pronunciation of the sound (mantra) while doing japa. It is how to say the mantra in a particular rhythm so the deity is pleased. It is the rhythm to be followed to chant a mantra. All mantras are named traditionally with a Chandas. (SRSAV-14,P.3.22).

c. Devta: The deity of the mantra or governing deity of a mantra. Every mantra has a devta. The devta is invoked by the mantra to come into the heart. There are so many streams of supreme consciousness in this vast universe. The aspirant attracts the stream of consciousness of that particular deity of that mantra as rays of the light.

d. Bija: The seed syllable that created the mantra and contains the mantra within itself, like the seed that creates the tree. Every mantra has a bija (seed syllable) from which it sprouts or originates, which creates the mantra. Bija mantras are used to awaken the different energy centres located in the human body. Namah Sivaya comes form the bija 'Haum'. Hare Krshna mahamantra comes from "Kleem'. Hrim, shrim, klim, Aiam, Hoom, Yum, Bum, Rum, Lum etc are some of the bijamantras which can be called subtle injections used to inject some additional power in a mantra. As per the need such bija mantras are added to mantras. We call them potential mantras, because they contain dormant, potential energy of different forces. Each of the powers or forces in the world has its own bija mantra. Those bija mantras are just like little bombs, the type of time bomb which explodes just at the right moment. Just as you plant a seed in the earth and from that a giant tree grows up, giving thousands of fruits, such is the power of the bija mantra. With the practice of anushthana, prolonged mantra repetition for a fixed period of time and number of malas, and regular sadhana, the power of the mantra is awakened. When that power is awakened, the consciousness takes the form of the mantra and then the real work of the mantra begins.

e. Tattva: Element is a character of a mantra. It can also be called the key to the mantra. It is the destination to be reached by firm resolution of the aspirant. Every mantra possesses the nature of a particular element (such as Earth, Water, Fire, Air and the sky) and a particular guna (such as Sat, raj and tam). Even elements are worshiped as per the nature of the mantra. Thus each mantra has a seer (rishi) who composed it, a rhythm or meter (Chhanda) which determines its sound, and a deity (devata) who presides over it and manifests when the mantra is correctly pronounced. It also contains a seed syllable (bija) which imparts to it manifesting power (Shakti) and a support (tatva) which makes it strong or stable until it delivers the intended result.

\section{Limbs of Mantra Yoga}

There are 16 limbs of Mantra yoga which ensure the aspirant' success on the path of mantra yoga. They are as follows:

Bhakti (devotion)- Faith and devotion to the mantra and the deity is the most important condition to succeed in mantra yoga.

Shudhi (purification) refers to self-purification. It stands for the purification of the body, mind and spirit. It also stands for the purification of the place and direction.

i. Asana: Refers to that thing on which the aspirant sits. Asanas made of woolen, kusha, resham, Mriga-charma, baghambar, blanket etc. are considered good. Asana also stands for some particular, steady, comfortable postures in which the aspirant sits while chanting Mantra.

ii. Panchang Sevan: Gita, Sahasranam, Stavan, Kavach and Hridaya nyas are collectively known as panchang sevan. Gita-that which is sung. Sahasranam means experiencing the vastness of the Supreme Being. Stuti is experiencing the vastness and associating it with the heart. Kavach is having protection from the obstacles arising from sadhana. Hridayanyasa- is entering the mysteris of Mantra through the heart.

iii. Achara (conduct): Aspirant should bear a good moral conduct.

iv. Dharana (concentration): Concentration is binding the mind to one place.

v. Divyadesh Sevan (self-identification)

vi. Prana Kriya (Pranayama or breath regulation): Prana means breath, ayam is lengthening or widening through control. When breathing is controlled so as to retain the breath, it is pranayama.

vii. Mudra (hand locks): Mudra can be described as psychic, emotional, devotional and aesthetic gestures or attitueds [16-18].

viii. Tarpana (libations): Offering different objects/ materials to the deity.

ix. Havan: Is offering oblations to the burning fire of Yagya. Mantra chanting bears no fruit without havan.

x. Bali: Sacrificing evils like pride, lust, anger and any other evil habits and practices is bali.

xi. Yaag: (contemplation and inner worship) Worshiping the deity is called Yaag. 
xii. Japa: (chanting) refers to mantra chanting. Japa means the repetition of a mantra so it encompasses all uses of mantras. However, Japa is most commonly associated with a fixed number of repetitions of a mantra. Usually a string of beads, known as a Mala, with a set number of beads would be used to keep countone repetition per bead [19-25]. Traditionally, most Malas have 108 "counter" beads. and a "guru" bead used to indicate where to begin and end. Sometimes shorter malas with 54 or 27 beads can be used with longer mantras. The mala used during mantra practice acts as an anchor for the mind. If a bird is flying over the ocean in search of land, it may use a piece of driftwood to rest upon until it finds land. The mala serves the same purpose for the mind as the piece of wood for the bird. It is an anchor. Just as whispered, vocalized and mental repetitions are used to stay with the practice, the mala too is used to stay focused. The movement of the mala keeps track of time and the numbers of repetition.

The movement also holds your mind and does not allow it to slip. So, a mala should always be used during mantra sadhana. There are five different kinds of malas accepted in the yogic tradition - tulsi, rudraksha, rakta-chandan (red sandalwood), shweta chandan (white sandalwood), and crystal. Traditionally, it is believed that Vaishnavas use tulsi, Shaivas use rudraksha and Shaktas use crystal. But this is a religious belief; a spiritual aspirant can use any kind of mala to attain different states. Japa is of three kinds. Japa done aloud is the lowest; Japa done in low tones is the middle; Japa done mentally is the best. (Kularnava Tantra 15.54).

a. Dhyana (meditation): when concentration becomes deeper it is called meditation. Uninterrupted stream of the content of consciousness is meditation [26-33].

b. Samadhi (absorption): Is the state of self-realization. It is the complete absorption of the individual self with the supreme self. In this state the awareness of the external world is absent. There is the experience of the eternal self, akhanda swaroop. This is the level of consciousness called samadhi, trance or turiya. That state becomes Samadhi when there is only the object appearing without the consciousness of one's own self. It may sound a lot but for the sincere practitioner, who continues to practice step-by-step, it all comes together naturally.

\section{Conclusion}

Mantra Yoga is the union of the individual soul with the supreme soul by the chanting of the manta. It is said that one can achieve the ultimate salvation or union with supreme consciousness by chanting the mantras, which is the aim of mantra yoga. The manta itself is Devta (deity), manifesting in a sound body. Constant repetition of the mantra with faith, devotion and purity bestows on the aspirant illumination, peace, eternal bliss and salvation. By constant repetition of the manta the aspirant imbibes the virtues and powers of the deity that presides over the mantra. Mantras are in the form of praise and appeal to the deities, craving for help and mercy.

For example, the chanting of Gayatri Mantra bestows on the aspirant's discrimination and salvation. Recitation of Surya Mantra bestows health, long life, vigour, brilliance. Recitation of Aditya-hriday strotam in the early morning is highly beneficial. Lord Rama conquered Ravana through the recitation of this strotam imparted by Agastya Rishi. Rhythmical vibrations of sound give rise to forms. Recitation of the mantras gives rise to the formation of the particular figure of the deity.

\section{References}

1. Rigveda-7.59.12.

2. Yajurveda-3.60.

3. Gita- 10: 25 .

4. Linga Puran-8.5.124, 125.

5. Mahabharat Ashwa-44.8.

6. Manusmriti 4.46 .

7. Yoga sutra- 1.27 .

8. Yoga sutra-1.28.

9. Yoga sutra-1.29.

10. Yoga sutra-3.1.

11. Yoga sutra-3.2.

12. Yoga sutra-3.3.

13. Yoga Sutra-4.1.

14. Yogavashistha-6.1.8.1.39.

15. Kularnava Tantra 15.54.

16. Swami Sivananda Saraswati (2007) Realization of Mantra.

17. Pranav, Pandya (2006) Anatar Jagat ki Yatra ka Gyan Vigyan, Haridwar, Vedmata Gayatri Trust, Shantikunj, UK 1: 108.

18. Complete Works of Swami Vivekananda/Volume 3/Bhakti-Yoga/The Mantra: Om: Word and Wisdom.

19. Maharshi, Raman (2013) Mantra Japa.

20. Aurobindo Sri CWSA Kena and other Upanishads 18: 29-31.

21. Aurobindo Sri CWSA Letters on Poetry and Art 27.

22. Swami Vishnu-devananda in his book "Meditation and Mantras."

23. Devananda, Swami, Vishnu (2013) Meditation and Mantra.

24. Saraswati, Swami Satyananda (2007) Mantra Yoga.

25. Acharya, Sri Ram, Sharma (1998) SRSAV-14, Gayatri sadhana ki vaigyanik Prishtabhumi-3.22, Mathura, UP: Akhand Jyoti Sansthan Mathura.

26. Acharya, Sri Ram, Sharma (1998) SRSAV-14, Gayatri sadhana ki vaigyanik Prishtabhumi-3.23, Akhand Jyoti Sansthan Mathura.

27. Acharya, Sri Ram, Sharma (1998) SRSAV-14, Gayatri sadhana ki vaigyanik Prishtabhumi-4.15-16, Akhand Jyoti Sansthan Mathura.

28. Acharya, Sri Ram, Sharma (1998) SRSAV-19, Shabd Brahma- Nad Brahma, P.2.16, Mathura, UP: Akhand Jyoti Sansthan Mathura. 
29. Acharya, Sri Ram, Sharma (1998) SRSAV-19, Shabd Brahma- Nad Brahma, P.1.36-37, Mathura, UP: Akhand Jyoti Sansthan Mathura.

30. Acharya, Sri Ram, Sharma (2013) Super Science of Gayatri, Vedmata Gayatri Trust Shantikunj, Hardwar, p. 59.

31. Saraswati, Swami Satyananda (1999) Asana Pranayam Mudra Bandha Yoga Publication Trust, Munger, Bihar, India, P.421.

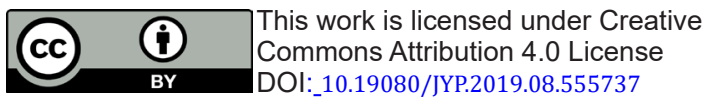

32. David, B.Wolf (2003) Examining the effect of meditation techniques on psychological functioning. Sage Publication, Research on social practice 13(1): 27-42.

33. Dheera, Govinda Das (1999) Effect of the Hare Krishna Mahamantra on stress, depression and the three Gunas.

\begin{tabular}{l} 
Your next submission with Juniper Publishers \\
will reach you the below assets \\
- Quality Editorial service \\
- Swift Peer Review \\
- Reprints availability \\
- E-prints Service \\
- Manuscript Podcast for convenient understanding \\
- Global attainment for your research \\
- Manuscript accessibility in different formats \\
( Pdf, E-pub, Full Text, Audio) \\
- Unceasing customer service \\
Track the below URL for one-step submission \\
https://juniperpublishers.com/online-submission.php \\
\hline
\end{tabular}

